\title{
GOLPE/IMPEACHMENT - UMA ANÁLISE DISCURSIVA SOBRE A SIGNIFICAÇÃO DO MESMO
}

\author{
Mariana Jantsch de Souza
}

Submetido em 04 de junho de 2018.

Aceito para publicação em 03 de agosto de 2018.

Cadernos do IL, Porto Alegre, n. ${ }^{\circ}$ 56, novembro. p. 257-272

\section{POLÍTICA DE DIREITO AUTORAL}

Autores que publicam nesta revista concordam com os seguintes termos:

(a) Os autores mantêm os direitos autorais e concedem à revista o direito de primeira publicação, com o trabalho simultaneamente licenciado sob a Creative Commons Attribution License, permitindo o compartilhamento do trabalho com reconhecimento da autoria do trabalho e publicação inicial nesta revista.

(b) Os autores têm autorização para assumir contratos adicionais separadamente, para distribuição não exclusiva da versão do trabalho publicada nesta revista (ex.: publicar em repositório institucional ou como capítulo de livro), com reconhecimento de autoria e publicação inicial nesta revista.

(c) Os autores têm permissão e são estimulados a publicar e distribuir seu trabalho online (ex.: em repositórios institucionais ou na sua página pessoal) a qualquer ponto antes ou durante o processo editorial, já que isso pode gerar alterações produtivas, bem como aumentar o impacto e a citação do trabalho publicado.

(d) Os autores estão conscientes de que a revista não se responsabiliza pela solicitação ou pelo pagamento de direitos autorais referentes às imagens incorporadas ao artigo. A obtenção de autorização para a publicação de imagens, de autoria do próprio autor do artigo ou de terceiros, é de responsabilidade do autor. Por esta razão, para todos os artigos que contenham imagens, o autor deve ter uma autorização do uso da imagem, sem qualquer ônus financeiro para os Cadernos do IL.

\section{POLÍTICA DE ACESSO LIVRE}

Esta revista oferece acesso livre imediato ao seu conteúdo, seguindo o princípio de que disponibilizar gratuitamente o conhecimento científico ao público proporciona sua democratização.

http://seer.ufrgs.br/cadernosdoil/index

Quinta-feira, 22 de novembro de 2018. 


\title{
GOLPE/IMPEACHMENT - UMA ANÁLISE DISCURSIVA SOBRE A SIGNIFICAÇÃO DO MESMO
}

\author{
COUP/IMPEACHMENT - A DISCURSIVE ANALYSIS \\ ABOUT THE MEANING OF THE SAME
}

\begin{abstract}
Mariana Jantsch de Souza*
RESUMO: Neste texto, analisamos, a partir da teoria do discurso de M. Pêcheux, o par Golpe/Impeachment considerado como uma das produções discursivas envolvidas no processo de rejeição e de destituição da presidenta Dilma Rousseff. O par em análise representa os saberes de duas Formações Discursivas antagônicas (FD1 e FD2). Nesse contexto, designam o mesmo acontecimento a partir de posições opostas e em embate. Cada um traz o interdiscurso de uma forma específica para o fio do discurso, promovendo movimentos discursivos diferentes, mas com o mesmo objetivo: legitimar os saberes da FD em que se inscrevem. Entendemos que as diferenças e as contradições que essas designações põem em movimento ajudam a compreender o funcionamento da ideologia materializada no discurso.
\end{abstract}

PALAVRAS-CHAVE: Análise de Discurso; Democracia; Golpe/Impeachment.

ABSTRACT: In this text, we analyze, from the theory of the speech of M. Pêcheux, the pair Coup / Impeachment considered as one of the discursive productions involved in the rejection and dismissal process of the president Dilma Rousseff. The pair in analysis represents the knowledge of two antagonistic Discursive Formations (FD1 and FD2). In this context, they designate the same event from opposing and clashing positions. Each one brings the interdiscourse in a specific way to the thread of the discourse, promoting different discursive movements, but with the same objective: to legitimize the knowledge of the FD in which they are inscribed. We understand that the differences and contradictions that these designations put into motion help us to understand the workings of ideology embodied in discourse.

KEYWORDS: Discourse Analysis; Democracy; Coup/Impeachment.

\section{Considerações iniciais}

Neste texto, nossas reflexões centram-se no desfecho do que estamos entendendo como processo político, jurídico e social de rejeição e de destituição da Presidenta Dilma Rousseff. Apresentamos uma análise dos termos golpe e impeachment considerando duas formações discursivas (FDs), em que para cada uma corresponde uma forma diferente de tratar e de significar o mesmo acontecimento. A primeira, chamada de FD1, é representativa de um discurso de não aceitação da diferença, posicionando-se contra a reeleição de Dilma Rousseff e contra seus supostos eleitores. Esta é nomeada como FD anti-Dilma. A segunda, chamada de FD2, nomeada como próDilma, é representativa de um discurso favorável à reeleição de Rousseff e de não aceitação de práticas discursivas inscritas no âmbito da FD1.

Para realizar a análise proposta, apresentamos o contexto de produção e circulação dos termos em pauta nos dois processos discursivos considerados (antiDilma/FD1 e pró-Dilma/FD2). Observamos, nas materialidades analisadas, movimentos de rejeição e destituição de Dilma, de um lado, e movimentos de resistência, de outro. 
Nosso olhar analítico centra-se no percurso discursivo que cada termo expõe, com os movimentos de saberes que os subjazem. Nesse caminho, observamos o memorável no âmbito dos saberes de cada FD, através das categorias do interdiscurso e da memória discursiva, bem como os movimentos metafóricos e os efeitos polissêmicos envolvidos nesses processos de significação do mesmo.

\section{Golpe/Impeachment: do surgimento e uso dos termos no processo de rejeição e de destituição de Dilma Rousseff}

A reeleição de Dilma Rousseff, em 2014, não foi aceita no âmbito dos saberes da FD1. Desde então, observamos um intenso processo de rejeição à Presidenta materializado nas práticas discursivas da referida FD. Esse movimento de rejeição foi além da repercussão da reeleição e, ato contínuo, passamos a um movimento de destituição, que se consolidou a partir da evocação/convocação de um processo políticojurídico de impedimento. Na outra face da moeda, observamos uma reação a esses movimentos no âmbito dos saberes da FD2.

Essa situação instaurou-se discursivamente de forma que para cada domínio de saber correspondia uma forma de designar o processo político, jurídico e social que estávamos vivenciando. Aqueles que se inscrevem no âmbito dos saberes da FD1, utilizaram (e utilizam) a palavra impeachment, enquanto aqueles que se inscrevem no âmbito dos saberes da FD2 recorreram (e recorrem) à palavra golpe.

Antes de nos determos no funcionamento discursivo dessas designações, importa explicitar, mais amiúde, as condições de produção dessas designações.

Logo após a eleição de 2014, manifestações contra Dilma e sua reeleição aconteceram em diferentes cidades brasileiras. Em primeiro de novembro de 2014, em tais manifestações os gritos de "Fora Dilma, e leva o PT junto", já eram acompanhados pela palavra impeachment. Ou seja, o movimento para promover a destituição de Dilma começou nessa época, por meio do pedido de impeachment nos protestos contra seu governo (ATO, 2015; PROTESTO, 2014).

Adiante, apresentamos algumas imagens para ressaltar a cronologia do uso dos termos em análise e, também, para evidenciar a forma e a intensidade com que foram empregados nos discursos em pauta. Assim, as imagens que seguem são apenas ilustrativas e não serão objeto de análise.

(Fonte: PROTESTO..., 2014).

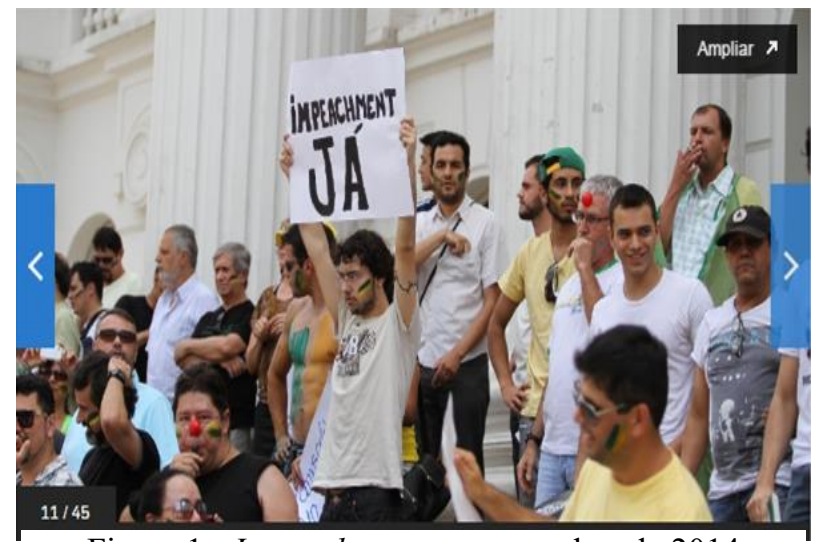

Figura 1 - Impeachment em novembro de 2014 
(Fonte: PROTESTO..., 2015).

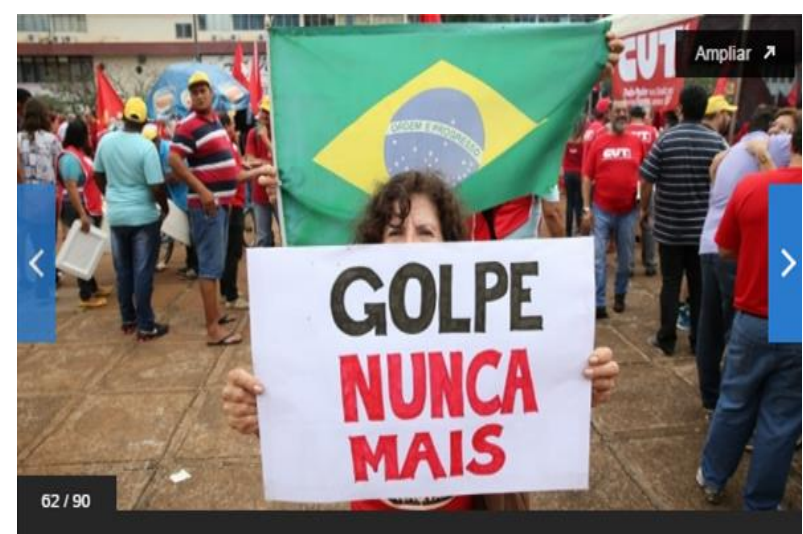

Figura 2 - Golpe em março de 2015

(Fonte: É IMPEACHMENT..., 2016).

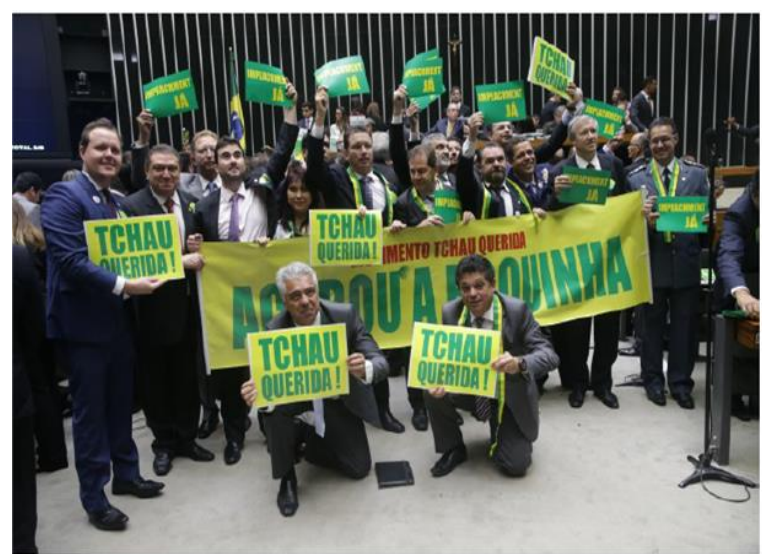

Figura 3 - Impeachment no Congresso

No mês de março de 2015, já estava em circulação a reação ao pedido de impeachment. Nos protestos realizados ao longo do ano de 2015 e de 2016 o binômio esteve sempre presente, conforme podemos observar nas imagens que seguem.

No mês de março de 2016, o par Golpe/Impeachment circulava nas ruas, nos protestos e no espaço virtual com força e intensidade (ATOS, 2015). Igualmente, na Câmara dos Deputados circulavam livremente os termos golpe e impeachment, como num clima de campanha eleitoral entre os congressistas. Os termos já eram usados diferentemente, junto com outras expressões.

(Fonte: O GOLPE..., 2016).

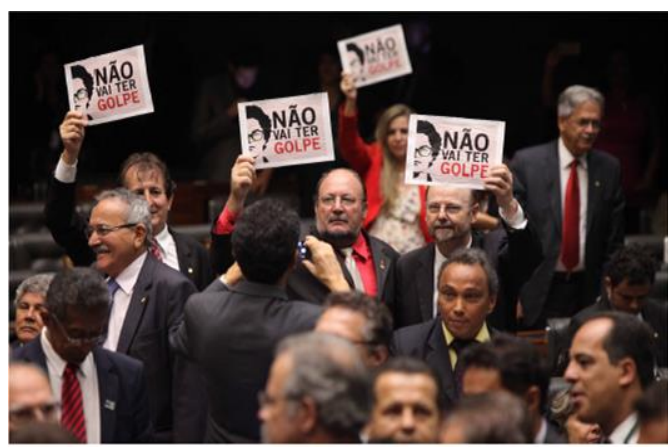

Figura 4 - Golpe no Congresso 
É preciso esclarecer que, neste trabalho, não abordaremos os aspectos estritamente jurídicos do impeachment. É dizer, não entraremos na discussão acerca da legitimidade ou não da destituição da Presidenta. Não discutiremos a existência ou inexistência de crime de responsabilidade, embora tenhamos um juízo formado a esse respeito. Nosso foco não é o nível jurídico-constitucional do processo de destituição, mas, sim, a discursivização do processo, levando em conta o recorte discursivo realizado. Nosso objetivo, portanto, é compreender as práticas discursivas que materializaram esse processo.

\section{Designação e Análise de Discurso: do funcionamento discursivo do par Golpe/Impeachment}

Neste contexto, entendemos que o uso dos termos golpe e impeachment não se limita a um simples gesto de nomeação, pois, dadas as relações que procuram representar e expor, designam todo o processo que aqui analisamos. Assim, se, no início, o termo impeachment era utilizado como nome do pedido de afastamento definitivo (ou seja, o nome dado a um processo político e jurídico), com o tempo, tornou-se uma designação para a situação vivida no cenário político nacional. Do mesmo modo, a palavra golpe deixou de ser simplesmente um outro nome ao pedido de impeachment e passou a designar todo o contexto no qual foi produzida.

Ao evocar o contexto de sua produção, o uso de cada termo também funciona como uma forma de posicionamento, pois, ao utilizar uma palavra e não outra, o sujeito demarca de qual espaço discursivo enuncia, revelando suas filiações, sua posição de dizer, a FD que o afeta em suas práticas discursivas.

O par em análise representa os saberes de duas FDs antagônicas, aqui denominadas de FD1 (anti-Dilma) e FD2 (pró-Dilma). Tais palavras, neste contexto, referem-se a mesma situação a partir de posições opostas e em embate. Cada uma, por estabelecer relações próprias com a exterioridade, traz o interdiscurso de uma forma específica para o fio do discurso, em processos discursivos diferentes, mas com o mesmo objetivo: legitimar os saberes da FD em que se inscrevem e as posições sustentadas em relação à rejeição e à destituição da Presidenta.

Assim, entendemos que tais termos representam um contexto discursivo determinado, funcionando como uma 'cápsula discursiva' ${ }^{1}$ : um pequeno elemento que representa, como num processo metonímico, todo o movimento de saberes engajado em sustentar e legitimar o discurso das FDs em que se inserem.

Para pensar a noção de designação, recorremos às considerações de Eduardo Guimarães, estudioso do tema que diferencia nomeação e designação. Segundo ele, a nomeação diz respeito ao "funcionamento semântico pelo qual algo recebe um nome" (GUIMARÃES, 2005, p. 9). Trata-se da relação nome/objeto, que está no nível da indicação da existência ou da classificação da coisa da qual se fala.

Partindo dessa definição, sustentamos que os termos em análise ultrapassam o nível da nomeação, pois sua compreensão exige que sejam considerados além da relação de nomeação que estabelecem com o processo a que se referem. Isso porque

\footnotetext{
${ }^{1}$ A expressão cápsulas discursivas foi utilizada por Jael S. Sigales-Gonçalves no VIII Seminário Nacional sobre Linguagem e Ensino (VIII SENALE), em 2016, quando tomamos conhecimento da mesma. Depois disso, passamos a utilizá-la em nossas reflexões, mas apresentando-a da forma como a entendemos. Sigales-Gonçalves aprofunda suas reflexões sobre tal expressão em sua tese de doutorado.
} 
encerram em si todo o complexo de relações discursivas envolvidas nesse processo, como cápsulas discursivas. Aqui, a ambiguidade que a expressão "nesse processo" pode produzir é proveitosa, pois os termos em análise (golpe/impeachment) sintetizam a rede de relações envolvidas no processo de significação dos próprios termos e também no processo de rejeição e de destituição de Dilma. Desse modo, para entender que cada termo funciona como uma tomada de posição em relação a determinado processo discursivo é preciso atentar para as relações que cada um estabelece com o contexto de sua produção.

Para desenvolver essas reflexões e compreender os termos em questão na direção em que estamos indicando, entendemos que designar é muito mais do que simplesmente nomear. Nesse sentido, Guimarães nos diz que designação é a

\begin{abstract}
significação de um nome enquanto sua relação com outros nomes e com o mundo recortado historicamente pelo nome. A designação é algo abstrato, mas linguístico e histórico. Ou seja, é uma relação linguística (simbólica) remetida ao real, exposta ao real. Por isso um nome não é uma palavra que classifica objetos, incluindo-os em certos conjuntos. Para mim tal como considera Rancière os nomes identificam objetos (2003, p. 54, grifo nosso).
\end{abstract}

Nas práticas discursivas analisadas, o uso de cada termo, por si só, estabelece e expõe determinadas relações com a exterioridade, revelando, com isso, a dimensão sócio-histórica e ideológica do discurso. Este olhar sobre os termos nos permite considerar as suas significações em relação "com outros nomes e com o mundo recortado historicamente pelo nome". E, assim, observar, em nosso corpus, que o papel da designação "não se reduz ao papel de indicar a existência ou de servir de rótulo para alguma coisa. Um nome, ao designar, funciona como elemento das relações sociais que ajuda a construir e das quais passa a fazer parte" (GUIMARÃES, 2003, p. 54).

Os nomes golpe e impeachment, ao discursivizarem o mesmo processo (mas em direções opostas e em confronto), funcionam como elementos das relações que ajudam a constituir nesse processo e, também, as materializam. Cada termo funciona como uma tomada de posição, entendida como efeito de identificação do sujeito enunciador em relação à forma-sujeito de determinada FD. Assim, o uso desses termos, nesse contexto de produção, não é aleatório: vincula o seu enunciador a certa $\mathrm{FD}$ e, com isso, ao mesmo tempo, o coloca em posição antagônica com outros saberes. Por esse efeito de identificação, a utilização de um dos termos implica em interdição do uso do outro termo. Com esse funcionamento, golpe e impeachment passam a constituir as relações de força que se materializam no discurso e deixam de representar um mero processo de nomeação, classificação ou qualificação do objeto a que remetem.

Feitas essas considerações, começamos a compreender que essas palavras funcionam como cápsulas discursivas, representando toda a urdidura de relações mobilizadas, nesse contexto de produção, pelos dois domínios de saber que sustentam cada uma. Seus funcionamentos evocam da memória discursiva diferentes suportes para justificar as posições sustentadas, mantendo a produção de sentidos em direções dissonantes, mantendo o embate entre as FDs.

A FD1 mobiliza a memória do movimento Caras Pintadas que culminou com o impeachment do Presidente Fernando Collor de Mello e, a partir dessa memória, estabelece relações com o processo atual de modo a reafirmar os sentidos produzidos no âmbito de seus saberes. De outro lado, a FD2 mobiliza a memória da ditadura militar vivida no Brasil e, a partir dessa retomada, também estabelece relações com o processo 
atual para reafirmar a legitimidade de seu discurso. As diferenças e contradições que essas designações põem em movimento ajudam a compreender o funcionamento da ideologia materializada no discurso.

Essas palavras fazem funcionar um complexo processo de significação que relaciona as duas FDs ao interdiscurso e à memória discursiva, atualizando diferentes efeitos de sentido já em circulação para sustentar posições de dizer diferentes e divergentes. Conforme Indursky, essas relações diferentes e específicas com a memória discursiva são possíveis porque cada FD é regulada por uma memória discursiva, que é determinada ideologicamente:

\begin{abstract}
constata-se que uma FD é regulada por uma memória discursiva que faz aí ressoar os ecos de uma memória coletiva, social. Por outro lado, a memória discursiva que se depreende de uma FD não é plena, não é saturada, pois nem todos os sentidos estão autorizados ideologicamente a ressoar em uma FD. Essa é a diferença que se estabelece entre o memorável, que é de ordem do "todos sabem, todos lembram", e a memória discursiva que é de ordem ideológica. É o ideológico que responde pela natureza lacunar de uma FD e da memória discursiva por ela representada (2011, p. 87, grifo nosso).
\end{abstract}

Essas múltiplas memórias retomadas e realocadas pelas designações em pauta são mobilizadas para ocupar espaços específicos em processos discursivos específicos (num discurso e não em outro, promovendo, ao mesmo tempo, movimentos de legitimação e deslegitimação de saberes). É compreendendo esse movimento de resgate de memórias e o lugar que passam a ocupar que podemos observar a ideologia funcionando no discurso, pois o que pode, deve e convém ser retomado no âmbito do discurso de cada FD é ideologicamente determinado.

Para pensar os sentidos que as duas designações produzem, importante pensar as noções de interdiscurso e memória discursiva. Compreendemos, conforme propõe Indursky, que

\begin{abstract}
se o interdiscurso remete, como nos diz Orlandi, à memória do dizer, isto significa que tudo que já foi dito inscreve-se no interdiscurso e, se isso ocorre é porque o interdiscurso constitui-se de um complexo de formações discursivas. Ou seja: todos os sentidos já produzidos aí se fazem presentes, e não apenas os sentidos que são autorizados pela FormaSujeito. E, se é assim, nada do que já foi dito pode dele estar ausente. O interdiscurso não é dotado de lacunas. Ao contrário. Ele se apresenta totalmente saturado. Esta é a natureza do interdiscurso: reunir todos os sentidos já produzidos por vozes anônimas, já esquecidas. E é por comportar todos os sentidos que ele se distingue da memória discursiva (2011, p. 86, grifo nosso).
\end{abstract}

Nessa perspectiva, não consideramos interdiscurso como sinônimo de memória discursiva. Para traçar essa diferença, entendemos que o primeiro é saturado de sentidos, abrange todos os dizeres (passados e presentes) e todas as possibilidades de dizer (os dizeres futuros). Nele estão os sentidos que "todos sabem, todos lembram", ou seja, estão os saberes memoráveis, passíveis de serem retomados.

Diferente é a memória discursiva, porque mantém suas relações não com esse todo saturado que é o interdiscurso, mas com a FD em que o discurso é produzido. Ou seja, tem um compromisso com a rede de filiações da FD: "se a memória discursiva se refere aos enunciados que se inscrevem em uma FD, isto significa que ela diz respeito 
não a todos os sentidos, como é o caso do interdiscurso, mas aos sentidos autorizados pela Forma-Sujeito no âmbito de uma FD” (INDURSKY, 2011, p. 86-7).

Nesse caminho, compreendemos que as retomadas de dizeres são feitas a partir de certa posição de dizer, determinada por certa FD, que é regulada por certa Formação Ideológica (FI), ou seja, as retomadas dos saberes interdiscursivos obedecem a um funcionamento ideológico. Por isso, entendemos que a memória discursiva faz parte do interdiscurso, mas abrange uma região de saberes mais restrita: é um recorte desse todo saturado determinado pela posição-sujeito e pela FD em que o sujeito do discurso se inscreve. A memória discursiva, portanto, é lacunar e está circunscrita pelo que pode, deve ou convém ser dito e lembrado no âmbito dos saberes da FD.

Então, como numa via de mão dupla, se a memória discursiva está circunscrita pelo dizível em certa FD, também está circunscrita pelo não dizível na FD: "ao ser refutado um sentido, ele o é também a partir da memória discursiva que aponta para o que não pode ser dito na referida FD. A memória discursiva ainda tem um outro funcionamento: é em função dela que certos sentidos são "esquecidos" (INDURSKY, 2011, p. 87). É por meio da memória discursiva, determinada ideologicamente, que os efeitos de apagamento e esquecimento de certos dizeres são produzidos. No entanto, a produção desses efeitos não acarreta o apagamento ou esquecimento definitivo desses saberes, pois eles permanecem, inexoravelmente: "um sentido pode desaparecer de uma FD, mas não pode ser apagado do interdiscurso, onde ele permanece recalcado" (INDURSKY, 2011, p.87).

São essas relações e diferenças entre memória discursiva e interdiscurso que podemos observar nas designações em análise: cada uma mobiliza diferentes elementos do interdiscurso para sustentar-se e para discursivizar o mesmo processo. Todos esses elementos são passíveis de serem retomados, mas, dadas as diferentes relações ideológicas que subjazem a cada FD, estão autorizadas as retomadas de uns e desautorizadas a retomada de outros.

Golpe e impeachment significam o mesmo acontecimento, mas percorrendo caminhos divergentes. Isso é possível porque essas significações do mesmo são produzidas no âmbito de FDs diferentes, reguladas por memórias discursivas diferentes. Observar esses termos nos faz retomar a lição de Pêcheux, quando afirma que "as palavras, expressões e proposições etc., recebem seu sentido da formação discursiva na qual são produzidas" (2009a, p. 147), porque

\footnotetext{
o sentido de uma palavra, de uma expressão, de uma proposição etc., não existe 'em si mesmo' (isto é, em sua relação transparente com a materialidade significante), mas, ao contrário, é determinado pelas posições ideológicas que estão em jogo no processo sócio-histórico no qual as palavras, expressões e proposições são produzidas (isto é, reproduzidas). Poderíamos resumir essa tese dizendo: as palavras, expressões e proposições etc., mudam de sentido segundo as posições sustentadas por aquele que as empregam, o que quer dizer que elas adquirem seu sentido em referência a essas posições, isto é, em referência às formações ideológicas nas quais essas posições se inscrevem (PÊCHEUX, 2009a, p. 146-7, grifo nosso).
}

Sendo assim, para compreender como o mesmo processo de rejeição e de destituição da Presidenta é discursivizado em direções diametralmente opostas a partir das designações golpe e impeachment, precisamos observar os processos discursivos em que se inserem. Voltemos, então, às designações, as suas FDs e aos movimentos de recorte realizados no interdiscurso (por meio da memória discursiva). 
A FD1 defende que o processo vivido em nosso cenário político deve ter como desfecho o impedimento da Presidenta e, portanto, é nesse discurso que se (re)utiliza a designação impeachment. O uso dessa designação sustenta-se nos efeitos de rejeição à Dilma e aos seus supostos eleitores que o discurso da FD1 produz. Nesse contexto de produção, o uso desse termo mobiliza a memória do impeachment do Presidente Collor, conforme já ressaltado. Subjaz a esse movimento de memória a reafirmação da legalidade e legitimidade do processo de destituição da Presidenta: assim como foi legal e legítima a destituição de Collor, o é a de Rousseff.

O processo de impedimento de Collor foi instaurado a partir de denúncias e investigações de esquemas de corrupção. Esta é a marca principal que envolve a memória do caso Collor de Mello, cujo desfecho foi a saída definitiva do Presidente, o que sugere a veracidade das denúncias. Ressaltamos que não houve impedimento, pois Collor renunciou antes do encerramento do processo de impeachment. No entanto, mesmo assim, tal episódio ficou marcado na memória discursiva brasileira como impeachment e será assim tratado em nossas reflexões.

De outro lado, a memória do impeachment de Collor está fortemente marcada por um movimento popular que tomou as ruas para, num grito coletivo contra a corrupção, pedir o impeachment do Presidente. Ressoa, no contexto atual, a mobilização popular intensa que colaborou para o desfecho de Collor: grande parte da população brasileira foi para as ruas protestar, pedir o afastamento definitivo de um Presidente corrupto, exigindo um novo Presidente. Assim, no âmbito da FD1 e de sua memória discursiva, o papel da população é associado a uma memória muito positiva: o povo reagiu, requereu seus direitos indo às ruas.

Rememorar o episódio Collor, no contexto de produção discursiva dos saberes da FD1, retoma efeitos de sentido positivos em relação à democracia e ao povo brasileiro. Explicamos. O resgate dessas memórias funciona aproximando os dois aspectos citados do impeachment de 1992 ao processo de impeachment de 2016, quais sejam: corrupção e atuação popular. Esses fatores são (re)significados para reforçar a legitimidade e a necessidade de afastamento da Presidenta e, do mesmo modo, a legitimidade e a necessidade da atuação da população (indo às ruas protestar até que o impeachment se concretize).

Essa memória associa a corrupção investigada no processo de Collor à situação de Dilma (e de todo o cenário político brasileiro) em razão de uma operação federal de combate à corrupção, capitaneada pela Polícia Federal e pelo Ministério Público Federal. Derivada de operações menores que iniciaram em 2008, em 2014 foi deflagrada a Operação Lava Jato para investigar a corrupção no alto escalão da política brasileira. No decorrer das investigações, vários políticos foram indiciados e processados. Dentre esses, há muitos nomes do partido de Dilma. Desde então, o PT era (é) noticiado como o mais corrupto (BRASIL, 2016; OPERAÇÃO..., 2016).

É a partir dessas condições de produção que esse movimento de memória e de produção de efeitos de sentido, na FD1, associa a Presidenta à corrupção e inflama a população a reagir. Tomando o contexto de Collor e a retomada do bordão "impeachment já!", temos, parafrasticamente, o seguinte funcionamento dessas memórias nas práticas discursivas em análise: reagimos, em 1992, à corrupção de Collor e conseguimos tirá-lo da presidência, portanto, precisamos reagir, hoje, e tirar Dilma do poder.

Deslocando esses sentidos para o momento atual, o processo de ressignificação dessa memória traz o passado político brasileiro como um exemplo a ser seguido. E, 
parafrasticamente, funciona na seguinte direção: vivemos isso no passado e fizemos o correto, estamos vivenciando isso novamente e temos o dever de agir corretamente novamente. Diante dos efeitos de sentido que sustentam a designação impeachment, no discurso da FD1 o impedimento de Dilma Rousseff surge como a única saída para a situação social e política brasileira, como a solução correta e como sendo dever da população exigi-la. Portanto, observamos que nesse intrincado processo de significação em que é produzida e utilizada a designação impeachment, todos os efeitos de sentido mobilizados convergem para a consolidação de uma aura positiva em torno do processo de rejeição e de destituição da Presidenta.

De outro lado, e numa direção oposta, a FD2 recorta do interdiscurso a memória da ditadura militar brasileira para discursivizar os acontecimentos políticos relativos aos movimentos de rejeição e de destituição de Dilma. Essa discursivização se dá promovendo movimentos de resistência, consolidando o discurso da FD2 como um contradiscurso. Por isso, é (re)utilizado, no âmbito desse discurso, o termo golpe para significar o processo de rejeição e de destituição em questão. Esse movimento de memória busca deslegitimar a destituição de Dilma, pois assim como o regime militar foi um abuso e um excesso, o é a retirada de Dilma da presidência. Assim como foi ilegítima a tomada de poder pelos militares, é ilegítima a tomada de poder pelos adversários da Presidenta.

O golpe militar de 1964 refere-se a um conjunto de eventos contra o então Presidente da República, João Goulart, ocorridos em 31 de março, que culminaram com a tomada de poder pelos militares. Desfazendo a ordem constitucional vigente, os militares encerraram ilegitimamente o governo democraticamente eleito. Instaurava-se, com isso, uma ordem política autoritária que perdurou até 1985 (GOLPE..., 2016; DITADURA..., 2016).

Os sentidos negativos que são retomados desse passado referem-se à tomada de poder de forma ilegal e ilegítima, ao autoritarismo do regime militar e às diversas arbitrariedades vivenciadas ao longo da exceção política (cassação de direito políticos, censura, redução dos direitos e garantias individuais do cidadão frente ao poder do Estado, repressão aos opositores e movimentos sociais por meio de muita violência).

Assim como observamos no âmbito da FD1, mas em uma direção diametralmente oposta, as memórias postas em funcionamento pelo discurso da FD2 convergem para a produção de efeitos de sentido que consolidam uma aura negativa em torno do processo de rejeição e de destituição de Dilma. Então, na contramão do movimento que a FD1 realiza, o afastamento da Presidenta é significado de forma negativa no discurso da FD2, e o passado político brasileiro ressurge como um exemplo a não ser seguido. Considerando essas memórias discursivas e o discurso em que são alocadas, temos, parafrasticamente, o seguinte funcionamento: se no passado sofremos com a retirada ilegítima de um Presidente e com a tomada de poder por um grupo igualmente ilegítimo, hoje não será diferente; portanto, temos o dever de agir e impedir um novo golpe à democracia brasileira.

Ressaltamos, ainda, que o par golpe/impeachment remete à memória da ditadura militar por outro viés. Na época em que foi instaurado o regime militar circulavam em discursos antagônicos os termos golpe e revolução para discursivizar a tomada de poder pelos militares - num processo de significação muito semelhante ao que analisamos no contexto do movimento de rejeição e de destituição de Dilma Rousseff.

De um lado, os sujeitos favoráveis ao regime militar utilizavam o termo revolução para designar a tomada de poder pelos militares e o regime político por eles 
instaurado $^{2}$. De outro lado, os sujeitos contrários à ditadura utilizavam o termo golpe para referir os mesmos acontecimentos, mas, no então contexto de produção, o termo normalmente surge associado a um modificador que o adjetiva: golpe militar.

Essa discursivização das relações de forças antagônicas a partir de duas designações ressoa no contexto do processo de impedimento de Dilma, apontando para a forma como o poder é retirado da Presidenta. Para aqueles que entendem que é legítimo o impedimento o termo utilizado é impeachment, sendo legítimo retirá-la do poder. Paralelamente, no passado, aqueles que entendiam ser legítima a retirada do Presidente João Goulart do poder utilizavam o termo revolução. Diversamente, para aqueles que entendem que é ilegítimo o impedimento da Presidenta o termo é golpe, sendo ilegítimo retirá-la do poder. Do mesmo modo, no passado, aqueles que entendiam ser ilegítima a destituição do Presidente, usavam o termo golpe (militar).

Desse modo, impeachment está para revolução, assim como golpe está para golpe (militar). Podemos observar uma mesma direção de significação em relação aos quatro termos. No âmbito das designações impeachment e revolução, a retirada do(a) Presidente(a) do poder é vestida com efeitos de sentidos positivos: é legítima, legal, necessária, sendo apresentada como um caminho benéfico para a nação. No entanto, no âmbito das designações golpe e golpe (militar), a retirada do(a) Presidente(a) do poder é marcada por efeitos de sentido negativos, pois a ênfase está no fato de o Presidente(a) ser legítimo e democraticamente eleito. Por isso, a forma legítima de retirá-lo do poder também deve ser democrática. Assim, é ilegítimo e ilegal destituir o(a) Presidente(a).

Observamos, ainda, que, ao longo do processo de rejeição e de destituição, as designações golpe e impeachment desdobraram-se em diferentes bordões utilizados para fazer ressoar os saberes das FD1 e FD2. Assim, o que iniciou sua produção como um simples gesto de nomeação passou a representar um complexo processo de designação e, discursivamente, desenvolveu-se, produzindo diferentes enunciados, tais como os que apresentamos no quadro a seguir:

\begin{tabular}{|l|l|}
\hline FD2 & FD1 \\
\#AceitaDilmaVez & \#SaiDilmaVez \\
$\begin{array}{l}\text { Não vai ter golpe } \\
\text { Não vai ter golpe, vai ter luta }\end{array}$ & Vai ter impeachment \\
$\begin{array}{l}\text { Contra o Golpe } \\
\text { Golpe nunca mais } \\
\text { Impeachment sem crime é golpe }\end{array}$ & Impeachment já! \\
Em defesa da democracia: Dilma fica! & Tchau querida! \\
\hline
\end{tabular}

\footnotetext{
${ }^{2}$ Indursky (1997) apresenta uma análise detalhada do discurso presidencial militar do período da ditadura brasileira em que podemos observar os efeitos de sentido que o termo revolução assume nesse processo discursivo. Também é possível compreender a relação de oposição que o termo revolução estabelece com o termo golpe.
} 


\begin{tabular}{|c|c|}
\hline Em defesa da democracia, contra o golpe & Fora Dilma \\
\hline Quadro 1 - Golpe/Impeachment e seus desdobramentos discursivos.
\end{tabular}

As imagens 1, 2, 3 e 4, apresentadas acima, mostram algumas das expressões apresentadas no quadro 1 . Todos esses desdobramentos do par em pauta inserem-se num regime de repetibilidade das memórias que subjazem cada designação e que sustentam os efeitos de sentidos que cada uma atribuiu ao mesmo acontecimento. Estão no eixo parafrástico da produção de sentidos: são formas diferentes de dizer o mesmo, de manter o processo de significação na mesma direção de produção de efeitos, estabilizando-o.

Observamos, ao longo de nossas análises, que as discursividades analisadas, não raro, funcionam como respostas umas das outras. Em razão dessa constante "conversa" entre as práticas discursivas analisadas, organizamos (no quadro 1) as expressões que derivam das designações golpe e impeachment em pares.

O funcionamento discursivo da repetição é questão central nas reflexões em $\mathrm{AD}$, pois, conforme Indursky, "a repetibilidade está na base da produção discursiva. É ela que garante a constituição de uma memória social que sustenta os dizeres, pois só há sentido porque antes já havia sentido" (2011, p. 88). Em nosso corpus, destacamos a repetição das designações em análise e seus desdobramentos em diferentes bordões para observar as variadas formas de insistir na legitimidade dos saberes das FDs em que são produzidas. Com isso, ressaltamos que, assim como as designações representam uma trama de relações com a exterioridade no âmbito de cada FD, os bordões selecionados mantêm esse funcionamento, repetindo e reforçando essas relações sócio-históricas materializadas na língua.

Os saberes de cada FD se inscrevem em uma matriz de sentidos que guia o processo de significação no âmbito do processo discursivo da FD. É a partir da matriz que são configurados os limites da produção de efeitos de sentido. Trata-se do que pode, deve ou convém ser dito (e lembrado) no âmbito da FD. Ou, nas palavras de Indursky, "se a matriz de sentidos se institui através do processo de repetibilidade, ela também coloca os limites dessa repetição, pois a matriz de sentido estabelece o que pode e deve ser dito no interior de uma FD" (2011, p. 68).

Sendo assim, os pares selecionados reverberam, pela repetição, os efeitos de sentido atribuídos ao processo de rejeição e de destituição. Com isso, funcionam guiando as significações para mantê-las na mesma direção em cada FD, estabilizandoas. Relembramos: para a FD1, todo o processo de rejeição e de destituição da Presidenta é discursivizado de forma a produzir uma aura positiva em torno desses acontecimentos, sugerindo a destituição da Presidenta como algo positivo e necessário para o Brasil e para os brasileiros. Já para a FD2, o processo em questão é discursivizado de forma a envolvê-lo em efeitos negativos, como sendo prejudicial para o Brasil e para os brasileiros.

Tais enunciados explicitam a insistência e a força dos movimentos de rejeição e de destituição, de um lado, e dos movimentos de resistência de outro. O primeiro par é formado por duas hashtags ${ }^{3}$. Não nos deteremos nas outras expressões apresentadas

\footnotetext{
${ }^{3} \mathrm{Na}$ linguagem das redes sociais, "hashtag é uma palavra-chave antecedida pela cerquilha (\#) que as pessoas geralmente utilizam para identificar o tema do conteúdo que estão compartilhando nas Redes Sociais" (Disponível em: <http://marketingdeconteudo.com/o-que-e-hashtag/>). As hashtags são identificadas pelo seu símbolo \#, funcionam como indexadores dos temas abordados na rede social e "viram hiperlinks dentro da rede, [...] outros usuários podem clicar nas hashtags (ou buscá-las em mecanismos como o Google) para ter acesso a todos que participaram da discussão. As hashtags mais
} 
porque, conforme já esclarecido, entendemos que todas mantêm o mesmo funcionamento e representam, de modo mais ou menos uniforme, o mesmo processo. Explicamos o contexto de sua produção para exemplificar e explicitar o clima de interlocução que subjaz aos demais pares.

Em abril de 2015, ocorreu mais um protesto contra Dilma e seu governo, sendo, portanto, mais um ato para intensificar os clamores por impeachment e insistir nos sentidos que essa palavra põe em funcionamento. Nesse mesmo dia, foi realizado um "tuitaço "4 pró Dilma proposto na fanpage oficial do Partido dos Trabalhadores ${ }^{5}$ como uma reação ao protesto antigoverno.

Esse primeiro par de expressões derivadas das designações em discussão, constrói-se a partir de um jogo de palavras. Temos um trocadilho em que a sentença "Aceita de uma vez", em razão da similaridade em nível fonético-fonológico, passa a ser representada como "Aceita Dilma vez". Ou seja, o nome Dilma surge como a representação gráfica das palavras "de uma", trocadilho possível graças à proximidade sonora entre as pronúncias. O mesmo processo se dá em \#SaiDilmaVez.

No plano do discurso da FD2 temos uma hashtag que põe em movimento sentidos a favor de Dilma e de seu governo, em defesa da manutenção de sua condição de Presidenta do Brasil. Funciona como um clamor: aceitem logo que ela é nossa Presidenta, porque ela é legítima, e deixem ela presidir; parem de boicotá-la pedindo o seu afastamento. Portanto: aceitem porque ela foi eleita democraticamente. Nesse caminho de significação, esse enunciado retoma e reafirma a relação entre Dilma e Democracia, um dos esteios em que se ancora a designação golpe no âmbito da FD2.

$\mathrm{Na}$ contramão desse discurso, temos a hashtag \#SaiDilmaVez, produzida no âmbito do discurso da FD1 e baseada no mesmo trocadilho. Aqui, ecoam os clamores pelo impeachment de Dilma, por isso ela deve "sair de uma vez". Igualmente, ecoam as justificativas que sustentam o impedimento de Dilma como algo positivo para a nação.

Outros desdobramentos são as expressões "golpe nunca mais" e "impeachment já!". A primeira retoma a associação ao golpe militar, reafirmando a deslegitimidade da destituição de Dilma: já vivemos um golpe uma vez, não viveremos de novo. A segunda associa o impedimento de Dilma ao impeachment de Collor, em que foi utilizado esse mesmo bordão, retomando um movimento de memória engajado em reafirmar a legitimidade e a necessidade do impeachment de Dilma, conforme já explicitamos. Observamos, assim, o mesmo funcionamento: já tivemos um impeachment em nossa história e foi o melhor caminho - hoje essa história se repete e o impeachment, novamente, é a solução.

Em todos os enunciados apresentados reverberam os saberes que legitimam o discurso de cada FD. Nesse contexto, entendemos que tais repetições operam como um excesso, pois buscam saturar os processos discursivos com determinados efeitos de

usadas no Twitter ficam agrupadas no menu Trending Topics" (Disponível em: $<$ https://pt.wikipedia.org/wiki/Hashtag $>$ ). Ou seja, no ambiente virtual, o uso das hashtags confere maior visibilidade ao tema abordado, porque a indexação permite que outros usuários o rastreiem. Além disso, se a hashtag alcançar um grande número de replicações ganhará ainda mais destaque através do menu Trending Topics.

"Estamos entendendo "tuitaço" como um evento virtual, que exige a atuação virtual de muitas pessoas, e que consiste em saturar a rede social de um determinado conteúdo através do uso e replicação insistente de uma determinada hashtag - nesse caso, a hashtag \#AceitaDilmaVez, produzida no âmbito do discurso da FD2. Considerando que essa hashtag foi uma resposta ao protesto citado, no âmbito da FD1 foi produzida, no mesmo ambiente virtual, uma réplica: \#SaiDilmaVez. 
sentido, funcionado como uma forma de interditar outros caminhos de significação, por não dar espaço para que outras possibilidades de significação dos mesmos acontecimentos sejam produzidas.

\section{Considerações finais}

A partir das designações golpe e impeachment, cada FD mobiliza memórias capazes de, além de legitimar as posições sustentadas, associar sentidos positivos ou negativos ao processo de rejeição e de destituição de Dilma Rousseff, conforme a direção da produção de efeitos de sentido no âmbito de cada FD. A FD1 associa sentidos positivos, para marcar, pela repetição, que o impeachment é correto e é legal, sendo apresentado, nesse discurso, como o melhor caminho para a nação (ou o único caminho benéfico para "todos"). Já a FD2 associa sentidos negativos ao processo de rejeição e de destituição da Presidenta para, com isso, repetir e insistir que não é um bom caminho, não é o correto, não é legal, ao contrário: é a pior opção porque pode desembocar em caminhos como os de um regime de exceção.

As duas FDs mobilizam os mesmos argumentos que, em síntese, são: defesa da democracia e solução da crise política e institucional. Na FD1, a defesa da democracia se dá por meio da destituição de Dilma; a solução da crise política e institucional também se dá somente com a destituição da Presidenta. Na FD2, defender a democracia é impedir a destituição ilegítima de Dilma; solucionar a crise política e institucional somente permitindo que a Presidenta legítima exerça seu poder institucional.

A insistência na legitimidade dos pressupostos que sustentam cada discurso (da FD1 e da FD2) funciona buscando estabilizar os processos de significação, controlando os sentidos e guiando as direções que se movimentam. Repetir tanto e de diferentes formas confere uma aparência de unicidade: os sentidos só podem ser esses. É dizer que, nas práticas discursivas inscritas na FD1, os sentidos atribuídos ao processo de rejeição e de destituição só podem ser construídos de forma positiva, levando a compreender que a destituição da Presidenta é necessária e legítima. De outro lado, nas práticas discursivas inscritas na FD2, os sentidos só podem ser negativos, levando a uma única conclusão: a destituição de Dilma é ilegítima e constitui um golpe à democracia.

Por fim, observamos que as duas FDs se posicionam em defesa da democracia, mas instauram processos discursivos que se movem em direções opostas. Discursivizam a mesma situação, usam argumentos semelhantes, mas propõem caminhos opostos. Ambas entendem que representam a vontade do povo, da maioria, o que serve para reforçar o suposto caráter democrático de cada discurso. Para o discurso da FD1, o "povo" quer o impeachment (como consequência do clamor das manifestações populares). Já para o discurso da FD2, o "povo" elegeu Dilma, que deve continuar ocupando esse espaço de poder, porque o povo assim o quis (e ainda quer). Sendo assim, nossas reflexões mostram como o mesmo pode ser significado diferentemente, mostrando o jogo de forças materializado na língua.

\section{REFERÊNCIAS}

ATOS pró-Dilma têm de 28 mil a 120 mil pessoas, divergem PM e sindicatos. $U O L$ 
Notícias. 13 mar. 2015. Disponível em: <https://noticias.uol.com.br/politica/ultimasnoticias/2015/03/13/entidades-sindicais-realizam-novos-atos-pro-dilma-em-11estados.htm\#fotoNav=33>. Acesso em 14 mai. 2016.

BRASIL. Ministério Público Federal. Entenda o caso. Disponível em: $<$ http://lavajato.mpf.mp.br/entenda-o-caso>. Acesso em 12 mai. 2016.

DITADURA Militar no Brasil.WIKIPÉDIA, a enciclopédia livre. Disponível em:

$<$ https://pt.wikipedia.org/wiki/Ditadura_militar_no_Brasil_(1964\%E2\%80\%931985)>. Acesso 12 mai. 2016.

É IMPEACHMENT ou golpe? Revista Piauí. 31 mar. 2016. Disponível em:

$<$ http://piaui.folha.uol.com.br/questoes-da-politica/e-impeachment-ou-golpe/>. Acesso em 15 mai. 2016.

EM DIA de protestos, petistas fazem 'tuitaço' a favor de Dilma. Folha de S. Paulo. 12 abr. 2015. Disponível em: http://www1.folha.uol.com.br/poder/2015/04/1615676-emdia-de-protestos-petistas-fazem-tuitaco-a-favor-de-dilma.shtml $>$ Acesso em 25 jan. 2017.

GOLPE de Estado no Brasil em 1964. WIKIPÉDIA, a enciclopédia livre. Disponível em: < https://pt.wikipedia.org/wiki/Golpe_de_Estado_no_Brasil_em_1964>. Acesso em 12 mai. 2016.

GUIMARÃES, Eduardo. Designação e espaço de enunciação: um encontro político no cotidiano. Letras, Santa Maria-RS, n 26, p. 53-62, jan./jun. 2003.

. Semântica do acontecimento: um estudo enunciativo da designação. Campinas, SP: Pontes, 2005.

INDURSKY, Freda. A fala dos quartéis e outras vozes. Campinas, SP: Editora da UNICAMP, 1997.

A memória na cena do discurso. In: INDURSKY; MITTMANN; FERREIRA

(Org.). Memória na/da análise do discurso. Campinas, SP: Mercado de Letras, 2011.

MANIFESTAÇÃO contra Dilma reúne 2.500 pessoas em São Paulo. Folha de S. Paulo. 1 nov. 2014. Disponível em: < http://www1.folha.uol.com.br/poder/2014/11/1542047ato-em-sao-paulo-pede-impeachment-de-dilma-e-intervencao-militar.shtml $>$. Acesso em 10 mai. 2016.

O GOLPE de 1964 e a instauração do regime militar. FGV CPDOC. Disponível em: $<$ http://cpdoc.fgv.br/producao/dossies/FatosImagens/Golpe1964>. Acesso em 20 mai. 2016.

OPERAÇÃO Lava Jato. WIKIPÉDIA, a enciclopédia livre. Disponível em: $<$ https://pt.wikipedia.org/wiki/Opera\%C3\%A7\%C3\%A3o_Lava_Jato $>$. Acesso em 12 mai. 2016.

ORLANDI, Eni P. Análise de Discurso - Princípios e Procedimentos. Campinas, SP: Pontes Editores, 2013.

PECHEUX, Michel. O discurso: estrutura ou acontecimento. Campinas, SP: Pontes Editores, 2008.

Semântica e Discurso. Campinas, SP: Editora da Unicamp, 2009.

PLENÁRIO da câmara discute processo de Impeachment. EBC. 14 abr. 2016.

Disponível em:

$<$ http://www.ebc.com.br/noticias/politica/2016/04/plenariodacamaracomecadiscutirproc essodeimpeachmentacompanheao $>$. Acesso em 15 mai. 2016.

PROTESTO contra Dilma reúne 6.000 em SP, mas exclui pedido de impeachment. UOL. 15 nov. 2014. Disponível em: <https://noticias.uol.com.br/politica/ultimasnoticias/2014/11/15/com-bolsonaro-protesto-contra-dilma-reune-mais-de-6000-mil-em- 
sp.htm\#fotoNav=17>. Acesso em: 15 mai. 2016.

PROTESTO em São Paulo pede o impeachment de Dilma. Revista EXAME. 1 nov. 2014. Disponível em: <http://exame.abril.com.br/brasil/protesto-em-sao-paulo-pede-oimpeachment-de-dilma/ > . Acesso em 10 mai. 2016.

SOUZA, Mariana Jantsch de. O Discurso de ódio na democracia brasileira: uma análise discursiva do processo de rejeição e de destituição da Presidenta Dilma

Rousseff. 2017. Tese (Doutorado em Letras) - Programa de Pós-Graduação em Letras, Universidade Católica de Pelotas. Pelotas, BR-RS. 